\title{
The Antioxidative Properties of Ganghwayakssuk (Artemisia princeps Pamp.) Extracts Added to Refrigerated Raw Chicken Nugget Batter against Lipid Oxidation
}

\author{
Ko-Eun Hwang ${ }^{1}$, Yun-Sang Choi², Ji-Hun Choi², Hack-Youn Kim², Hyun-Wook Kim¹, Mi-Ai Lee ${ }^{3}$, \\ Hae-Kyung Chung ${ }^{4}$, and Cheon-Jei Kim ${ }^{1,2 *}$ \\ ${ }^{1}$ Department of Food Science and Biotechnology of Animal Resources, Konkuk University, Seoul 143-701, Korea \\ ${ }^{2}$ Research Institute for Meat Science and Culture, Konkuk University, Seoul 143-701, Korea \\ ${ }^{3}$ World Institue of Kimchi, An Annex of Korea Food Research Institute, Seongnam 463-746, Korea \\ ${ }^{4}$ Department of Food and Nutrition, Hoseo University, Cheonan 336-795, Korea
}

\begin{abstract}
The efficiency of three concentrations (0.05, 0.1, and 0.2\%) of Ganghwayakssuk (Artemisia princeps Pamp.) extract on the susceptibility of raw chicken nugget batter to lipid oxidation was investigated after $0,3,7$, and $10 \mathrm{~d}$ of refrigerated storage at $4^{\circ} \mathrm{C}$. The $\mathrm{pH}$ and yellowness values of all treatments were higher than those of the control $(p<0.05)$. Additionally, the lightness and redness values of all treatments were lower than those of the control and as the amount of Ganghwayakssuk ethanolic extracts increased. At the end of the storage period (10 d), the peroxide values (POV), conjugated dienes (CD), and thiobarbituric acid reactive substances (TBARS) values were lower than those of the control. The results show that Ganghwayakssuk prevents lipid oxidation in raw chicken nugget batter.
\end{abstract}

Key words: antioxidants, Ganghwayakssuk (Artemisia princeps Pamp.), lipid oxidation

\section{Introduction}

Chicken meat and products have been used widely around the world. Consumption of chicken has become popular and has increased in many countries due to the nutrients and health effects of chicken (Choi et al., 2010). Chicken is chosen because of its comparatively low-fat content, high-nutritional value, and low-cost of manufacture. However, chicken meat products tend to oxidize because they include high levels of unsaturated fatty acids (Choi et al., 2010). Lipid oxidation is one of the main factors used to estimate meat quality due to the susceptibility of meat and meat products to oxidative degeneration (Morrissey et al., 1998). Lipid oxidation causes undesired odors and flavors and limits shelf-life. Oxidation reactions increase during cutting, cooking, salting, and refrigerated storage due to the interaction of unsaturated fatty acids and pro-oxidant substances such as non-

\footnotetext{
*Corresponding author: Cheon-Jei Kim, Department of Food Science and Biotechnology of Animal Resources, Konkuk University, Seoul 143-701, Korea. Tel: 82-2-450-3684, Fax: 82-2-444-6695, E-mail: kimcj@konkuk.ac.kr
}

heme iron (Goulas and Kontominas, 2007). A common way to prevent lipid oxidation is to use antioxidants (Tang et al., 2001).

Antioxidants are compounds that delay, retard, or prevent autoxidation processes (Shahidi and Wanasundara, 1992). Synthetic antioxidants such as butylated hydroxytoluene and butylated hydroxyanisole have excellent antioxidant effects on meat and meat products. For that reason, synthetic antioxidants are commonly used as food preservatives (Verhagen et al., 1994). However, synthetic antioxidants pose the possibility of health risk, toxicity, and carcinogenic effects (Branen, 1975) and have been linked with potential health problems (Hettiarachchy et al., 1996). Accordingly, meat and meat products are used to screen and select natural antioxidants as effective alternatives to prevent food deterioration (Kikuzaki and Nakatani, 1993). Natural antioxidants occur as plant phenolics in leaves, fruits, vegetables, roots, nuts, and seeds (Pratt and Hudson, 1990). Mathew and Abraham (2006) reported that plant phenolics scavenge free radicals and stop free radical chain reactions in meat and meat products.

Among the natural antioxidants, mugwort is widely used as a food or food additive. It contains eupatilin, 
acacetin, and eudesmane. Furthermore, it has been used to treat gastroenteritis, diarrhea, asthma, and many circulatory disorders (Ruy et al., 2004). Ganghwayakssuk (Artemisia princeps Pamp.), which is distributed on Ganghwa Island in Korea, has more polyphenol, eupatilin, and flavonoids than plants in other regions (Ruy et al., 2005). Ganghwayakssuk consists of bioactive compounds such as phenolics alkaloids, vitamins $\mathrm{A}, \mathrm{B}_{1}, \mathrm{~B}_{2}$, and $\mathrm{C}$, as well as various minerals (Lee et al., 1999). The protective effect of Ganghwayakssuk may be realized by adding it directly to meat or meat products during processing.

The objectives of this study were to determine the antioxidant activities of Ganghwayakssuk extracts, depending on various ethanol concentrations and the effects of Ganghwayakssuk ethanolic extracts in chicken nugget batter on $\mathrm{pH}$, color, peroxide value (POV), conjugated dienes (CD), and thiobarbituric acid reactive substances (TBARS) values during $10 \mathrm{~d}$ at $4^{\circ} \mathrm{C}$.

\section{Materials and Methods}

\section{Determination of antioxidant properties}

\section{Preparation of Ganghwayakssuk extract (GYE)}

Commercial samples of dried Ganghwayakssuk (Artemisia princeps Pamp.) were purchased from a local market at Ganghwa Island in Korea. After separating the leaves from the dried Ganghwayakssuk, they were ground using a blender (KA-2610, Jworld Tech, Korea) for a minute. Ground Ganghwayakssuk leaves (10 g) were extracted with $200 \mathrm{~mL}$ of distilled water, 50,70 , or $95 \%$ ethanol overnight in a shaker at room temperature. The extracts were filtered through filter paper $(\varnothing 110 \mathrm{~mm}$, cat. no. 1001 110, Whatman International Ltd, UK) and evaporated with a rotary evaporator (EYELA N-1000, Rikakikai Co. Ltd., Japan) at $<50^{\circ} \mathrm{C}$. After evaporation of each solvent, the Ganghwayakssuk extracts were dissolved in distilled water, 50,70 , or $95 \%$ ethanol $(5 \%$, v/w).

\section{Extraction yields}

Extraction yields for each solvent were calculated by subtracting the dried weight of plant material residue after extraction from the weight of the original plant material (Cha et al., 2009).

\section{Total phenol content}

The amount of total phenolics was determined using Folin-Ciocalteu reagent (Slinkard and Singleton, 1977). Aliquots of extract $(100 \mu \mathrm{L})$ were diluted with $4.5 \mathrm{~mL}$ of distilled water. After vortexing for $1 \mathrm{~min}, 100 \mu \mathrm{L}$ of Folin-Ciocalteu reagent was added and mixed using a vortex mixer. After $5 \mathrm{~min}, 300 \mu \mathrm{L}$ of $2 \% \mathrm{Na}_{2} \mathrm{CO}_{3}$ was added and mixed, and the absorbance was measured at $760 \mathrm{~nm}$. Gallic acid was used as the standard for the calibration curve. The total phenolic content was expressed as milligram gallic acid equivalents (GAE) per gram of sample $(\mathrm{mg} / \mathrm{g})$.

\section{DPPH radical scavenging activity}

The scavenging effects of GYE against DPPH radicals were determined according to the modified method of Brand-Williams et al. (1995). Briefly, $1 \mathrm{~mL}$ aliquot of each extract $(0.1-1.0 \mathrm{mg} / \mathrm{mL})$ was mixed with $4 \mathrm{~mL}$ of DPPH ethanolic solution $(100 \mu \mathrm{M})$. The reaction mixture was shaken well and incubated for $30 \mathrm{~min}$ at room temperature. The absorbance of the resulting solution was read at $517 \mathrm{~nm}$ using a UV-Vis spectrophotometer (Libra S22, Biochrom Ltd., UK) against a blank. The inhibitory percentage of DPPH was calculated according to the following equation:

$$
\begin{aligned}
& \text { Scavenging activity }(\%) \\
& \quad=\left[1-\left(\text { absorbance }_{\text {sample }} / \text { absorbance }_{\text {control }}\right)\right] \times 100
\end{aligned}
$$

\section{Reducing power}

GYE reducing power was determined according to the method of Oyaizu (1986). Briefly, $2.5 \mathrm{~mL}$ of extract with different GYE concentrations $(0.1-10 \mathrm{mg} / \mathrm{mL})$ was mixed with phosphate buffer $(2.5 \mathrm{~mL}, 0.2 \mathrm{M}, \mathrm{pH} 6.6)$ and potassium ferricyanide $\left[\mathrm{K}_{3} \mathrm{Fe}(\mathrm{CN})_{6}\right](2.5 \mathrm{~mL}, 1 \%)$, and the mixture was incubated at $50^{\circ} \mathrm{C}$ for $20 \mathrm{~min}$. An aliquot $(2.5 \mathrm{~mL})$ of trichloroacetic acid $(10 \%)$ was added to the mixture, which was centrifuged at $650 \mathrm{~g}$ (MSE Mistral 2000, London UK) for $20 \mathrm{~min}$. The supernatant $(2.5 \mathrm{~mL})$ was mixed with distilled water $(2.5 \mathrm{~mL})$ and $\mathrm{FeCl}_{3}(0.5$ $\mathrm{mL}, 0.1 \%$ ), and the absorbance was measured at $700 \mathrm{~nm}$ against a spectrophotometer blank. Increased absorbance of the reaction mixture indicated increased reducing power.

\section{Ferrous iron chelating ability}

Ferrous iron-chelating activity was measured according to the method of Yen and Chung (1999). The reaction mixture, containing GYE in ethanol $(0.1-1.0 \mathrm{mg} / \mathrm{mL})$, ferrous chloride $\mathrm{FeCl}_{2}(0.05 \mathrm{~mL}, 2 \mathrm{mM})$, and ferrozine $(0.2 \mathrm{~mL}, 5 \mathrm{mM})$, was adjusted to $5 \mathrm{~mL}$ with distilled water. The mixture was shaken well and incubated for 10 min at room temperature. The absorbance of the mixture 
was measured at $562 \mathrm{~nm}$ against a blank. The ability of the extracts to chelate ferrous iron was calculated using the following equation:

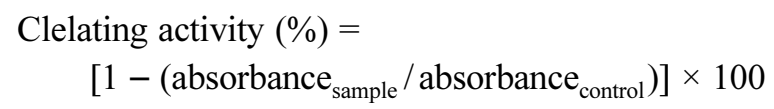

\section{Effects of Ganghwayakssuk extract on lipid oxida- tion in raw chicken nugget batter}

\section{Preparation of chicken nugget batter}

Fresh chicken breast meat (M. pectoralis major) and chicken skin were purchased from a local market. The chicken materials were initially ground through an 8-mm plate. The ground tissue was then placed in polyethylene bags, vacuum packaged using a vacuum packaging system (FJ-500XL, Fujee Tech, Korea), and stored at $0^{\circ} \mathrm{C}$ until required for product manufacture. Suitable amounts of the muscle and chicken skin were tempered at $4^{\circ} \mathrm{C}$ for $24 \mathrm{~h}$ prior to preparing the chicken nugget batter. The first step for the chicken nugget batter was to prepare the binder meat. Chicken breast meat (17\%) was homogenized and ground in a silent cutter (Cutter Nr-963009, Scharfen, Germany). $1.5 \% \mathrm{NaCl}, 0.3 \%$ sodium tripolyphosphate, and 3\% ice were mixed with the chicken breast meat and then added to the chicken skin. A temperature probe (Kane-May, KM330, Germany) was used to monitor the temperature of the emulsion, which was maintained at $<10^{\circ} \mathrm{C}$ during batter preparation. After emulsification of the binder meat, each portion of ground chicken breast meat was mixed with binder meat, and
50\% GYE (pH: 6.06 $\pm 0.02, L^{*}$-value: $29.65 \pm 0.21, \mathrm{a}^{*}-$ value: $2.06 \pm 0.24, b^{*}$-value: $\left.0.25 \pm 0.04\right)$ was added $(\mathrm{w} / \mathrm{w})$, according to the following formulation (Table 1): control (no antioxidant added); AC- 0.05 (0.05\% ascorbic acid); GYE-0.05 (0.05\% Ganghwayakssuk ethanolic extract); GYE-0.1 (0.1\% Ganghwayakssuk ethanolic extract); and GYE- 0.2 ( $0.2 \%$ Ganghwayakssuk ethanolic extract). A portion of the raw chicken nugget batter was packaged as mentioned earlier, stored under refrigeration $\left(4^{\circ} \mathrm{C}\right)$, and used for further analysis $(0,3,7$, and $10 \mathrm{~d})$.

$\mathrm{pH}$

The $\mathrm{pH}$ of $5 \mathrm{~g}$ samples blended with $20 \mathrm{~mL}$ distilled water for $60 \mathrm{~s}$ in a homogenizer (Ultra-Turrax T25, Janke and Kunkel, Germany) was determined with a $\mathrm{pH}$ meter (Model 340, Mettler-Toledo GmbH, Switzerland).

\section{Color}

Color measurements were taken with a colorimeter (Chroma meter CR-210, Minolta, Japan; illuminate C, calibrated with a white standard plate $\mathrm{L}^{*}=97.83, \mathrm{a}^{*}=$ $-0.43, \mathrm{~b}^{*}=+1.98$ ) using an 8 -mm diameter measuring area and a 50-mm diameter illumination area. Color values (CIE L $\left.{ }^{*}, a^{*}, b^{*}\right)$ were measured on internal samples and were taken from three different spots on the surface of each ground sample and averaged.

\section{Peroxide values (POV)}

Lipid extraction was conducted according to the method of Folch (Folch et al., 1957) using a chloroform:methanol solvent system (2:1). The lipid extracts were evaporated

Table 1. Raw chicken nugget batter formulations with various Ganghwayakssuk ethanolic extracts (GYE) levels

\begin{tabular}{|c|c|c|c|c|c|}
\hline \multirow{2}{*}{ Ingredients } & \multicolumn{5}{|c|}{ Treatments } \\
\hline & Control & AC- -0.05 & GYE-0.05 & GYE-0.1 & GYE-0.2 \\
\hline Chicken breast ground meat & 70 & 70 & 70 & 70 & 70 \\
\hline Chicken binder meat & 17 & 17 & 17 & 17 & 17 \\
\hline Chicken skin & 10 & 10 & 10 & 10 & 10 \\
\hline Ice & 3 & 3 & 3 & 3 & 3 \\
\hline Total & 100 & 100 & 100 & 100 & 100 \\
\hline Salt & 1.5 & 1.5 & 1.5 & 1.5 & 1.5 \\
\hline Sodium tripolyphosphate & 0.3 & 0.3 & 0.3 & 0.3 & 0.3 \\
\hline Ascorbic acid & 0 & 0.05 & 0 & 0 & 0 \\
\hline Ganghwayakssuk extracts & 0 & 0 & 0.05 & 0.1 & 0.2 \\
\hline
\end{tabular}

Control, no antioxidant; AC- 0.05 , raw chicken nugget containing ascorbic acid $0.05 \%$; GYE-0.05, raw chicken nugget batters containing Ganghwayakssuk ethanolic extract $0.05 \%$; GYE-0.1, raw chicken nugget batters containing Ganghwayakssuk ethanolic extract $0.1 \%$; GYE-0.2, raw chicken nugget batters containing Ganghwayakssuk ethanolic extract $0.2 \%$ 
and concentrated with a rotary evaporator (Rotary evaporator N-1000, Eyela, Japan), leaving the extracted lipids for POV analyses. Lipid extracted from the sample was determined by AOAC methods (1990). The lipid sample $(0.5 \mathrm{~g})$ was treated with $25 \mathrm{~mL}$ of solvent mixture (acetic acid:chloroform mixture, 3:2). The mixture was shaken thoroughly, and $1 \mathrm{~mL}$ of saturated potassium iodide solution was added. The mixture was kept in the dark for 10 min, $30 \mathrm{~mL}$ of distilled water was added, and the mixture was mixed. One $\mathrm{mL}$ of starch solution $(1 \%$, w/v) was added as an indicator. The peroxide value was determined by titrating the iodine liberated from potassium iodide with standardized $0.01 \mathrm{~N}$ sodium thiosulfate solutions. The POV was calculated as follows:

$$
\operatorname{POV}(\mathrm{meq} / \mathrm{kg})=(\mathrm{S}-\mathrm{B}) \times \mathrm{F} \times \mathrm{N} \times 1000 / \mathrm{W}
$$

[S = titration amount of sample; $\mathrm{B}=$ titration amount of blank; $\mathrm{F}=$ titer of $0.01 \mathrm{~N}$ sodium thiosulfate; $\mathrm{N}=$ normality of sodium thiosulfate; $\mathrm{W}=$ sample weight $(\mathrm{g})]$. The results are expressed as milliequivalent peroxide $\mathrm{O}_{2} / \mathrm{kg}$ meat.

\section{Conjugated dienes (CD)}

Lipid extraction was determined according to the method of Folch (Folch et al., 1957), using a chloroform:methanol solvent system $(2: 1)$. Conjugated diene formation was determined as described by Prasetyo et al. (2008). Extracted sample lipids (0.015 g) were massed into a $25 \mathrm{~mL}$ volumetric flask, brought to volume with isooctane, and mixed. The absorbance was read at 234 $\mathrm{nm}$ with isooctane used as the blank. The CD concentration was calculated using a $25200 / \mathrm{M} / \mathrm{cm}$ molar extinction coefficient, and the results are expressed as $\mu \mathrm{mol} / \mathrm{mg}$ meat lipid sample (Juntachote et al., 2006).

\section{Thiobarbituric acid reactive substances (TBARS)} values

Lipid oxidation was assessed in triplicate using the TBARS method of Tarladgis et al. (22) with minor modifications. A $10 \mathrm{~g}$ sample was blended with $50 \mathrm{~mL}$ distilled water for $2 \mathrm{~min}$ and then transferred to a distillation tube. The cup used for blending was washed with an additional $47.5 \mathrm{~mL}$ of distilled water, which was added to the same distillation flask with $2.5 \mathrm{~mL}$ of $4 \mathrm{~N} \mathrm{HCl}$ and a few drops of a silicone o/w antifoam agent (KMK-73, Shin-Etsu Silicone Co., Ltd., Korea). The mixture was distilled, and $50 \mathrm{~mL}$ of the distillate was collected. Five $\mathrm{mL}$ of $0.02 \mathrm{M}$ 2-thiobarbituric acid in 90\% acetic acid (TBA reagent) was added to a vial containing $5 \mathrm{~mL}$ of the distillate and mixed well. The vials were capped and heated in a boiling water bath for $30 \mathrm{~min}$ to develop the chromogen and then cooled to room temperature. Absorbances were measured using a UV/VIS spectrophotometer (Optizen 2120 UV plus, Mecasys Co. Ltd., Korea) at $538 \mathrm{~nm}$, against a blank prepared with $5 \mathrm{~mL}$ distilled water and $5 \mathrm{~mL}$ TBA-reagent. TBARS values were calculated from a standard curve $(8-50 \mathrm{nmol})$ of malondialdehyde (MDA), freshly prepared by acidification of TEP (1,1,3,3-tetraethoxy propane). Reagents were obtained from Sigma. TBARS levels were calculated as mg MDA/ kg samples.

\section{Statistical analysis}

An analysis of variance was performed on all the variables using the General Linear Model procedure of the SAS statistical package (SAS Institute, Inc., 2001). Duncan's multiple range tests $(p<0.05)$ was used to determine differences between treatment means.

\section{Results and Discussion}

\section{Antioxidant activity of the GYE depending on var- ious ethanol concentrations}

\section{Extraction yields}

Extraction yields of the Ganghwayakssuk, depending on the various ethanol concentrations were determined (Fig. 1). The extraction yields were 21.38, 26.07, 25.27, and $8.69 \%$ for the water, 50, 70 and $95 \%$ ethanol extracts,

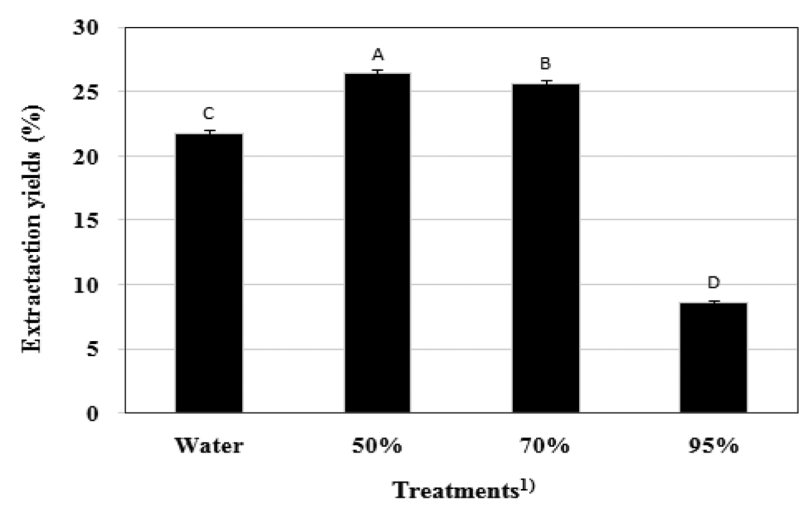

Fig. 1. Extraction yields (\%) from the Ganghwayakssuk extracts depending on various ethanol concentrations. ${ }^{\mathrm{A}-\mathrm{D}}$ Means sharing different letters are significantly different $(p<0.05)$.

${ }^{1)}$ Water, water extracts from Ganghwayakssuk; 50\%, 50\% ethanolic extracts from Ganghwayakssuk; 70\%, 70\% ethanolic extracts from Ganghwayakssuk; 95\%, 95\% ethanolic extracts from Ganghwayakssuk 


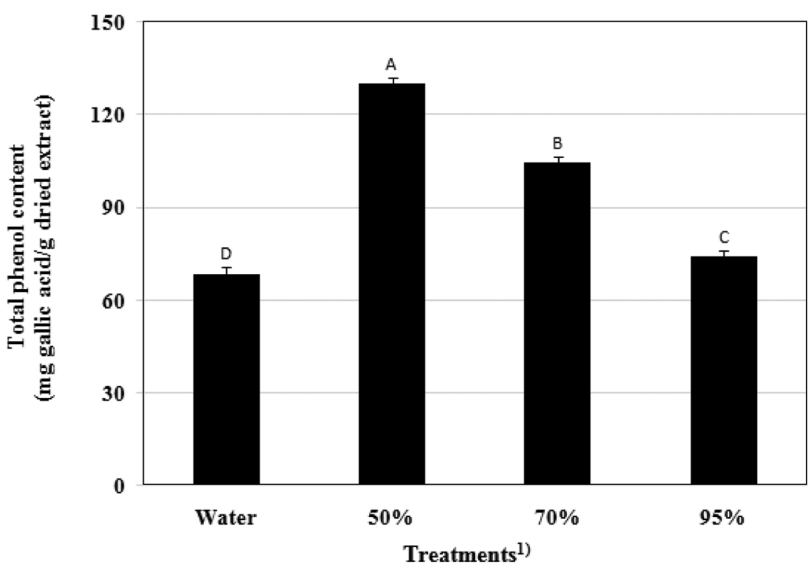

Fig. 2. Total phenol content (mg gallic acid/g dried extract) of Ganghwayakssuk extracts depending on various ethanol concentrations.

${ }^{\mathrm{A}-\mathrm{D}}$ Means sharing different letters are significantly different $(p<0.05)$.

${ }^{1)}$ Water, water extracts from Ganghwayakssuk; 50\%, 50\% ethanolic extracts from Ganghwayakssuk; 70\%, 70\% ethanolic extracts from Ganghwayakssuk; 95\%, 95\% ethanolic extracts from Ganghwayakssuk

respectively. The highest extraction yield was recorded for the $50 \%$ GYE, whereas the lowest was for $95 \%$ GYE.

\section{Total phenol content}

Total phenol content of the GYE depending on the various ethanol concentrations are presented in Fig. 2. In this study, $50 \%$ aqueous ethanol was more efficient at extracting the polyphenolic compounds than other ethanol concentrations. The total phenol content was 68.60, 130.00, 105.17 , and $74.23 \mathrm{mg}$ gallic acid/g in water, 50, 70 and 95\% GYE, respectively. Differences in the total phenol content of all samples were significant $(p<0.05)$. The $50 \%$ GYE had the highest total phenolic content, followed by the 70 and 95\% GYE, and water. Hong et al. (2007) showed that total polyphenol content of Artemisia princeps Pamp. was higher than the total flavonoid content, and that ethyl acetate extracts had higher total polyphenol content than other solvent extracts. Phenolic compounds are generally more soluble in polar organic solvents than in water. Phenolic compounds such as acid-phenols and their esters have antioxidative properties. They are secondary metabolites synthesized in plants and affect appearance, flavor, and oxidative stability (Cuvelier et al., 1992). Phenol compounds readily bind with protein and prompt various physiological activities in microbes that delay microbial growth (Antonia et al., 1990).

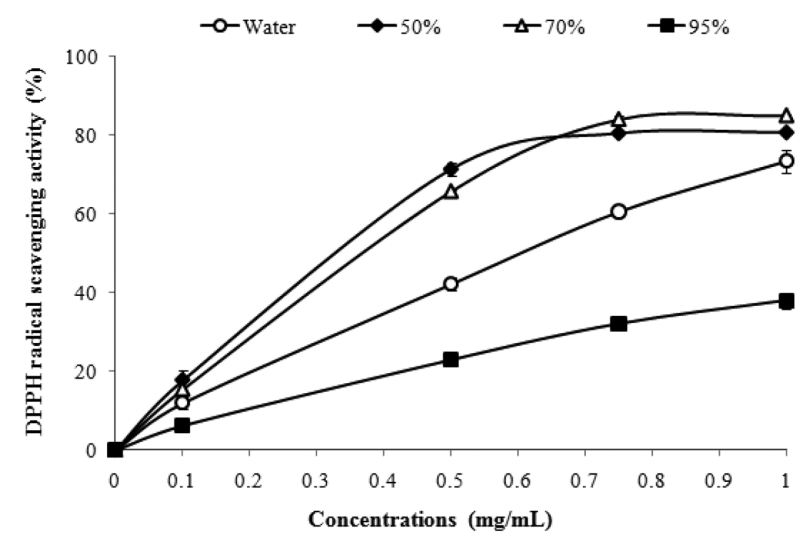

Fig. 3. DPPH free-radical scavenging activity of Ganghwayakssuk extracts depending on various ethanol concentrations.

Water, water extracts from Ganghwayakssuk; 50\%, 50\% ethanolic extracts from Ganghwayakssuk; 70\%, 70\% ethanolic extracts from Ganghwayakssuk; 95\%, 95\% ethanolic extracts from Ganghwayakssuk

\section{DPPH radical scavenging activity and reducing power}

The DPPH assay has been widely used to determine the free radical scavenging ability of potential antioxidants. The DPPH assay is most commonly used to evaluate the antioxidant activity of extracts, because this method is fast and easily available (Chang et al., 2002). DPPH radical scavenging activities of GYE, depending on the various ethanol concentrations, are presented in Fig. 3. The results indicated that 50 and $70 \%$ GYE exhibited slightly greater DPPH radical scavenging activity than water and 95\% GYE. Pack et al. (2002) showed that the electron donating abilities of mugwort are higher in ethanol extracts than water extracts by approximately $5-7 \%$. Park and Kim (2006) reported that the DPPH radical scavenging of the $70 \%$ ethanol mugwort extract is higher than water extracts. The water extract (100-1,000 ppm) ranged from 73 to $81 \%$ and that of ethanol extracts ranged from 74 to $92 \%$. Thus, the DPPH radical scavenging activity of GYE may be mostly related to their phenolic hydroxyl groups.

Reducing ability is the ability of a natural antioxidant to donate electrons. Reducing power is based on the ability of a solvent extract to reduce a $\mathrm{Fe}^{3+}$ ferricyanide complex to form a $\mathrm{Fe}^{3+}$ ferrous complex. The reducing power of the GYE, depending on the various ethanol concentrations are shown in Fig. 4. The reducing power of the treatments was ranked as follows: 50 (1.67) and 70\% (1.60) GYE > water (1.42) > 95\% GYE (0.60). Reducing properties are generally associated with reductions (Duh, 


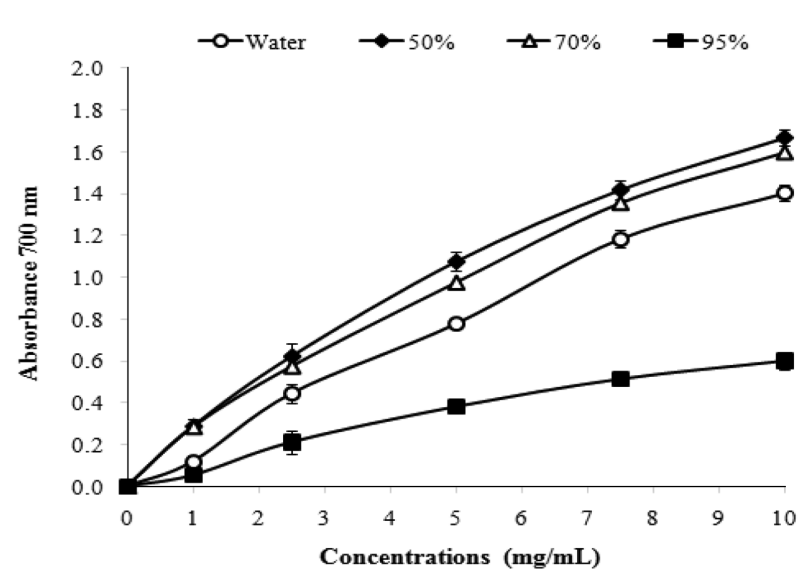

Fig. 4. Reducing power of Ganghwayakssuk extracts depending on various ethanol concentrations.

Water, water extracts from Ganghwayakssuk; 50\%, 50\% ethanolic extracts from Ganghwayakssuk; 70\%, 70\% ethanolic extracts from Ganghwayakssuk; 95\%, 95\% ethanolic extracts from Ganghwayakssuk

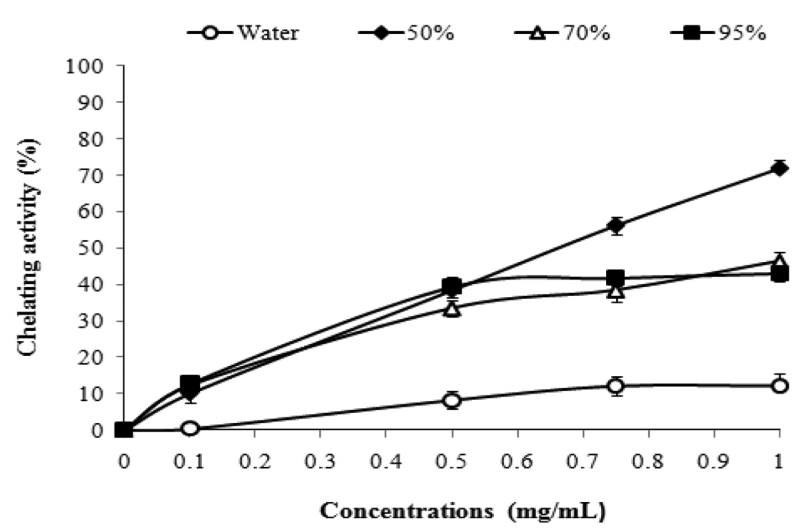

Fig. 5. Ferrous iron chelating ability of Ganghwayakssuk extracts depending on various ethanol concentrations. Water: water extracts from Ganghwayakssuk; 50\%: 50\% ethanolic extracts from Ganghwayakssuk; 70\%: 70\% ethanolic extracts from Ganghwayakssuk; 95\%: 95\% ethanolic extracts from Ganghwayakssuk

1998). Shimada et al. (1992) reported that the antioxidative action of reductions is based on the breeding of free radical chains by donated hydrogen atoms.

\section{Ferrous iron chelating activity}

We measured $\mathrm{Fe}^{2+}$ chelating activity of the GYE at concentrations ranging from 0.1 to $1.0 \mathrm{mg} / \mathrm{mL}$ (Fig. 5). The $50 \%$ GYE had the highest chelating activity, and differences in chelating activity of all samples were significant $(p<0.05)$. The chelating activity of $50 \%$ GYE was about $71.87 \%$ that of metal chelating activity. Other samples had metal chelating activity in the order of $70 \%$ GYE > $95 \%$ GYE $>$ water extract, with rates of $46.29,43.04$, and $12.24 \%$, respectively. Woo et al. (2010) showed that $\mathrm{Fe}^{2+}$ chelating effects were much higher in $80 \%$ ethanol $H$. pilosella flower extracts than water extracts. Generally, $\mathrm{Fe}^{2+}$ chelating activity is poorly correlated with phenol content (Graf and Eaton, 1990). However, DPPH radical scavenging increases with increasing phenol content and is positively correlated (Jeong et al., 2007). The 50\% GYE had the highest polyphenol content, DPPH radical scavenging, and chelating activity. Hence, 50\% GYE showed an interrelationship among polyphenol content, DPPH radical scavenging, and chelating activity.

\section{Effects of the GYE on lipid oxidation in chicken nugget batter during refrigerated storage}

\section{$\mathrm{pH}$ evaluation of chicken nugget batter}

Table 2 shows the $\mathrm{pH}$ values of raw chicken nugget batter formulated with GYE and then subjected to refrigerated storage for $10 \mathrm{~d}$. The $\mathrm{pH}$ of raw chicken nugget batter ranged from 6.08 to 6.25 . At the end of storage, the $\mathrm{pH}$ values of the raw chicken nugget batter were higher in treatments with added GYE than in the control. Similar trends in $\mathrm{pH}$ were observed in studies by Kim (2006), who indicated that the $\mathrm{pH}$ values of dietary mugwort and sardine oil treatments increased significantly compared to those of the control during storage. The $\mathrm{pH}$ values of all treatments gradually decreased as storage progressed. Jung et al. (2004) noted that the $\mathrm{pH}$ values of pork patties with added mugwort powder decrease during storage. Park et al. (2006) reported that the decrease in $\mathrm{pH}$ during storage was due to lactic acid generation by microorganisms, which generally increase as storage temperature and time increase. $\mathrm{pH}$ was affected by the GYE because the $\mathrm{pH}$ of GYE was higher than that of the raw meat.

\section{Color evaluations of chicken nugget batter}

Osburn and Keeton (1994) reported that the color of meat and meat products was affected by additives and caramel reaction during manufacturing. Table 2 shows the lightness (CIE L*), redness (CIE a ${ }^{*}$ ), and yellowness $\left(\mathrm{CIE} \mathrm{b}^{*}\right)$ values of the raw chicken nugget batter formulated with GYE after refrigerated storage for $10 \mathrm{~d}$. The lightness and redness values of the raw chicken nugget batter decreased with increasing GYE level $(p<0.05)$, whereas the yellowness values increased significantly with increasing GYE content $(p<0.05)$. Similar trends in color were observed in studies by Park et al. (2010) who investigated the quality characteristics of dried noodles with added lotus leaf powder. Gwon and Moon (2009) reported that adding green tea powder to sulgidduk results 
Table 2. Changes in pH and color values of raw chicken nugget batter containing Ganghwayakssuk ethanolic extracts (GYE) during refrigerated storage at $4^{\circ} \mathrm{C}$

\begin{tabular}{|c|c|c|c|c|c|c|}
\hline & $\begin{array}{c}\text { Storage } \\
\text { periods }(\mathrm{d})\end{array}$ & Control & AC-0.05 & GYE-0.05 & GYE-0.1 & GYE-0.2 \\
\hline \multirow{4}{*}{$\mathrm{pH}$} & 0 & $6.19 \pm 0.03^{\mathrm{Aa}}$ & $6.18 \pm 0.04^{\mathrm{Aa}}$ & $6.20 \pm 0.03^{\mathrm{Aa}}$ & $6.21 \pm 0.04^{\mathrm{Aa}}$ & $6.20 \pm 0.04^{\mathrm{Aa}}$ \\
\hline & 3 & $6.16 \pm 0.02^{\mathrm{BCb}}$ & $6.14 \pm 0.03^{\mathrm{Cb}}$ & $6.18 \pm 0.02^{\mathrm{ABb}}$ & $6.19 \pm 0.03^{\mathrm{Aab}}$ & $6.19 \pm 0.03^{\mathrm{Aa}}$ \\
\hline & 7 & $6.13 \pm 0.01^{\mathrm{BC}}$ & $6.10 \pm 0.02^{\mathrm{Cc}}$ & $6.15 \pm 0.02^{\mathrm{Ac}}$ & $6.16 \pm 0.03^{\mathrm{Ab}}$ & $6.16 \pm 0.02^{\mathrm{Ab}}$ \\
\hline & 10 & $6.10 \pm 0.03^{\mathrm{Bd}}$ & $6.08 \pm 0.02^{\mathrm{Cd}}$ & $6.12 \pm 0.01^{\mathrm{Ad}}$ & $6.14 \pm 0.01^{\mathrm{Ac}}$ & $6.13 \pm 0.01^{\mathrm{Ac}}$ \\
\hline \multirow{4}{*}{$\mathrm{L}^{*}$-value } & 0 & $62.88 \pm 0.32^{\mathrm{Ba}}$ & $63.58 \pm 0.46^{\mathrm{Aa}}$ & $61.03 \pm 0.27^{\mathrm{Ca}}$ & $59.99 \pm 0.20^{\mathrm{Da}}$ & $58.05 \pm 0.38^{\mathrm{Ea}}$ \\
\hline & 3 & $62.49 \pm 0.19^{\mathrm{Bb}}$ & $63.40 \pm 0.22^{\mathrm{Aa}}$ & $60.48 \pm 0.30^{\mathrm{Cb}}$ & $59.87 \pm 0.42^{\mathrm{Da}}$ & $58.00 \pm 0.35^{\text {Eab }}$ \\
\hline & 7 & $62.00 \pm 0.40^{\mathrm{Bc}}$ & $63.17 \pm 0.58^{\mathrm{Aa}}$ & $60.46 \pm 0.27^{\mathrm{Cb}}$ & $59.31 \pm 0.54^{\mathrm{Db}}$ & $57.48 \pm 0.66^{\mathrm{Eb}}$ \\
\hline & 10 & $60.76 \pm 0.17^{\mathrm{Bd}}$ & $62.50 \pm 0.22^{\mathrm{Ab}}$ & $60.03 \pm 0.27^{\mathrm{Cb}}$ & $58.68 \pm 0.30^{\mathrm{Dc}}$ & $56.78 \pm 0.43^{\mathrm{Ec}}$ \\
\hline \multirow{4}{*}{$a^{*}$-value } & 0 & $8.91 \pm 0.12^{\mathrm{Ba}}$ & $10.35 \pm 0.41^{\mathrm{Aa}}$ & $8.05 \pm 0.10^{\mathrm{Ca}}$ & $7.92 \pm 0.18^{\mathrm{Ca}}$ & $7.12 \pm 0.13^{\mathrm{Da}}$ \\
\hline & 3 & $8.81 \pm 0.10^{\mathrm{Bb}}$ & $9.29 \pm 0.17^{\mathrm{Ab}}$ & $7.73 \pm 0.18^{\mathrm{Cb}}$ & $7.60 \pm 0.20^{\mathrm{Cb}}$ & $6.67 \pm 0.15^{\mathrm{Db}}$ \\
\hline & 7 & $7.59 \pm 0.40^{\mathrm{Bc}}$ & $8.45 \pm 0.34^{\mathrm{Ac}}$ & $6.26 \pm 0.15^{\mathrm{CDc}}$ & $6.71 \pm 0.24^{\mathrm{Cc}}$ & $6.43 \pm 0.19^{\mathrm{Dc}}$ \\
\hline & 10 & $5.19 \pm 0.29^{\mathrm{Bd}}$ & $7.86 \pm 0.44^{\mathrm{Ad}}$ & $6.06 \pm 0.18^{\mathrm{Cd}}$ & $5.34 \pm 0.23^{\mathrm{Cd}}$ & $5.15 \pm 0.21^{\mathrm{Cd}}$ \\
\hline \multirow{4}{*}{$b^{*}$-value } & 0 & $12.03 \pm 0.37^{\mathrm{Ba}}$ & $11.42 \pm 0.27^{\mathrm{Ca}}$ & $12.20 \pm 0.22^{\mathrm{Ba}}$ & $12.37 \pm 0.14^{\mathrm{Ba}}$ & $13.39 \pm 0.22^{\mathrm{Aa}}$ \\
\hline & 3 & $11.64 \pm 0.15^{\mathrm{Bb}}$ & $11.05 \pm 0.20^{\mathrm{Cb}}$ & $11.79 \pm 0.38^{\mathrm{Bb}}$ & $11.74 \pm 0.20^{\mathrm{Bb}}$ & $13.36 \pm 0.29^{\mathrm{Aa}}$ \\
\hline & 7 & $11.29 \pm 0.36^{\mathrm{BCc}}$ & $10.98 \pm 0.15^{\mathrm{Cb}}$ & $11.71 \pm 0.28^{\mathrm{Bb}}$ & $11.70 \pm 0.55^{\mathrm{Bb}}$ & $12.39 \pm 0.31^{\mathrm{Ab}}$ \\
\hline & 10 & $10.63 \pm 0.12^{\mathrm{Dd}}$ & $10.87 \pm 0.21^{\mathrm{DCb}}$ & $11.50 \pm 0.10^{\mathrm{Bb}}$ & $11.18 \pm 0.42^{\mathrm{Cc}}$ & $12.06 \pm 0.47^{\mathrm{Ab}}$ \\
\hline
\end{tabular}

All values are mean $\pm \mathrm{SD}$ of the three replicates.

${ }^{\mathrm{A}-\mathrm{E}}$ Means sharing different letters in the same row are significantly different $(p<0.05)$.

${ }^{\mathrm{a}-\mathrm{d}}$ Means sharing different letters in the same column are significantly different $(p<0.05)$.

Control, no antioxidant; AC- 0.05 , raw chicken nugget containing ascorbic acid $0.05 \%$, GYE- 0.05 , raw chicken nugget batters containing Ganghwayakssuk ethanolic extract $0.05 \%$; GYE-0.1, raw chicken nugget batters containing Ganghwayakssuk ethanolic extract $0.1 \%$; GYE-0.2, raw chicken nugget batters containing Ganghwayakssuk ethanolic extract $0.2 \%$

in lower lightness and redness and higher yellowness values than the control. These results agree with those reported by Park and Kim (2006), who added mugwort powder to dried and cooked noodles. As a result, lightness and redness of the dried and cooked noodles decreased with increasing mugwort concentration $(p<0.05)$. Han et al. (2001) also noted that the color of food with added mugwort hah a lower lightness value and a higher yellowness value than that of the control. At the end of storage, raw chicken nugget batter samples with ascorbic acid showed the highest redness values $(p<0.05)$. According to Ahn and Nam (2004), ascorbic acid combined with beef at a level of $0.1 \%(\mathrm{w} / \mathrm{w})$ was very effective for maintaining redness of irradiated ground beef.

\section{POV, CD, and TBARS values of chicken nugget batter}

POV was assessed based on the quantity of hydroperoxides formed as primary oxidation products at the initial oxidation stage (Juntachote et al., 2006). Differences in POV values can be caused by differences in meat and sample preparation such as the application of sodium chloride and heat. Therefore, peroxides are very reactive and may actually decrease during storage of lipid-containing foods (Juntachote et al., 2007). The POV values of raw chicken nugget batter stored for $0,3,7$, and $10 \mathrm{~d}$ are illustrated in Table 3 . The POV values for all samples, except GYE 0.1 and 0.2, increased until $7 \mathrm{~d}$ and decreased thereafter, suggesting that the hydroperoxide decomposition rate was faster than the production rate after the induction period. El-Alim et al. (1999) showed similar results that the POV of frozen stored salted pork patties increases and thereafter decreases as time passes. Applying ascorbic acid and GYE significantly delayed changes in the peroxide values compared to the control for all days of storage. Generally, raw samples containing $0.2 \%$ GYE exhibited lower peroxide values than samples with lower GYE content, samples with ascorbic acid, and the control.

CD was evaluated based on the hydroperoxides formed in the extracted lipids of the raw chicken nugget batter. As meat begins to oxidize, the fatty acid double bonds shift to create conjugated systems that can be measured spectrophotometrically (Teets and Were, 2008). Peroxida- 
Table 3. Change in oxidative values of raw chicken nugget batter containing Ganghwayakssuk ethanolic extracts (GYE) during refrigerated storage at $4^{\circ} \mathrm{C}$

\begin{tabular}{|c|c|c|c|c|c|c|}
\hline & $\begin{array}{c}\text { Storage } \\
\text { periods }(\mathrm{d})\end{array}$ & Control & $\mathrm{AC}-0.05$ & GYE-0.05 & GYE-0.1 & GYE-0.2 \\
\hline \multirow{4}{*}{$\begin{array}{c}\text { POV } \\
(\mathrm{meq} / \mathrm{kg})\end{array}$} & 0 & $23.565 \pm 0.43^{\mathrm{Ad}}$ & $18.416 \pm 0.42^{\mathrm{Bd}}$ & $17.587 \pm 0.44^{\mathrm{Cd}}$ & $14.886 \pm 0.23^{\mathrm{Dd}}$ & $12.431 \pm 0.39^{\mathrm{Ed}}$ \\
\hline & 3 & $27.951 \pm 0.36^{\mathrm{Ac}}$ & $24.512 \pm 0.51^{\mathrm{Bc}}$ & $21.831 \pm 0.20^{\mathrm{Cc}}$ & $19.638 \pm 0.34^{\mathrm{Dc}}$ & $17.726 \pm 0.21^{\mathrm{Ec}}$ \\
\hline & 7 & $38.476 \pm 0.41^{\mathrm{Aa}}$ & $33.143 \pm 0.32^{\mathrm{Ba}}$ & $33.093 \pm 0.28^{\mathrm{Ba}}$ & $29.593 \pm 0.17^{\mathrm{Cb}}$ & $27.019 \pm 0.38^{\mathrm{Db}}$ \\
\hline & 10 & $31.382 \pm 0.41^{\mathrm{Db}}$ & $30.087 \pm 0.52^{\mathrm{Eb}}$ & $32.255 \pm 0.32^{\mathrm{Cb}}$ & $38.590 \pm 0.26^{\mathrm{Aa}}$ & $34.609 \pm 0.66^{\mathrm{Ba}}$ \\
\hline \multirow{4}{*}{$\begin{array}{c}\mathrm{CD} \\
(\mu \mathrm{mol} / \mathrm{mg})\end{array}$} & 0 & $0.714 \pm 0.005^{\mathrm{Ad}}$ & $0.685 \pm 0.005^{\mathrm{Bd}}$ & $0.663 \pm 0.003^{\mathrm{Cd}}$ & $0.630 \pm 0.012^{\mathrm{Dd}}$ & $0.597 \pm 0.006^{\mathrm{Ed}}$ \\
\hline & 3 & $0.790 \pm 0.015^{\mathrm{Ab}}$ & $0.769 \pm 0.007^{\mathrm{Bc}}$ & $0.753 \pm 0.009^{\mathrm{Cb}}$ & $0.696 \pm 0.005^{\mathrm{Dc}}$ & $0.684 \pm 0.007^{\mathrm{Dc}}$ \\
\hline & 7 & $0.956 \pm 0.007^{\mathrm{Aa}}$ & $0.841 \pm 0.007^{\mathrm{Ba}}$ & $0.796 \pm 0.010^{\mathrm{Ca}}$ & $0.741 \pm 0.009^{\mathrm{Db}}$ & $0.716 \pm 0.005^{\mathrm{Eb}}$ \\
\hline & 10 & $0.766 \pm 0.003^{\mathrm{Bc}}$ & $0.794 \pm 0.005^{\mathrm{Ab}}$ & $0.682 \pm 0.005^{\mathrm{Dc}}$ & $0.794 \pm 0.007^{\mathrm{Ca}}$ & $0.754 \pm 0.006^{\mathrm{Aa}}$ \\
\hline \multirow{4}{*}{$\begin{array}{c}\text { TBA } \\
(\mathrm{MDA} / \mathrm{kg})\end{array}$} & 0 & $0.14 \pm 0.03^{\mathrm{Ad}}$ & $0.12 \pm 0.10^{\mathrm{Bd}}$ & $0.11 \pm 0.16^{\mathrm{Bd}}$ & $0.09 \pm 0.07^{\mathrm{Cd}}$ & $0.08 \pm 0.04^{\mathrm{Cd}}$ \\
\hline & 3 & $0.21 \pm 0.07^{\mathrm{Ac}}$ & $0.19 \pm 0.05^{\mathrm{Bc}}$ & $0.17 \pm 0.17^{\mathrm{Cc}}$ & $0.15 \pm 0.06^{\mathrm{Cc}}$ & $0.11 \pm 0.04^{\mathrm{Ec}}$ \\
\hline & 7 & $0.28 \pm 0.07^{\mathrm{Ab}}$ & $0.24 \pm 0.07^{\mathrm{Bb}}$ & $0.21 \pm 0.16^{\mathrm{Cb}}$ & $0.19 \pm 0.06^{\mathrm{Db}}$ & $0.16 \pm 0.05^{\mathrm{Eb}}$ \\
\hline & 10 & $0.37 \pm 0.15^{\mathrm{Aa}}$ & $0.32 \pm 0.12^{\mathrm{Ba}}$ & $0.31 \pm 0.16^{\mathrm{Ca}}$ & $0.28 \pm 0.11^{\mathrm{Da}}$ & $0.25 \pm 0.10^{\mathrm{Ea}}$ \\
\hline
\end{tabular}

All values are mean $\pm \mathrm{SD}$ of the three replicates.

${ }^{\mathrm{A}-\mathrm{E}}$ Means sharing different letters in the same row are significantly different $(p<0.05)$.

${ }^{\mathrm{a}-\mathrm{d}}$ Means sharing different letters in the same column are significantly different $(p<0.05)$.

Control, no antioxidant; AC-0.05: raw chicken nugget containing ascorbic acid 0.05\%, GYE-0.05: raw chicken nugget batters containing Ganghwayakssuk ethanolic extract 0.05\%; GYE-0.1, raw chicken nugget batters containing Ganghwayakssuk ethanolic extract 0.1\%; GYE-0.2, raw chicken nugget batters containing Ganghwayakssuk ethanolic extract $0.2 \%$

tion of unsaturated fatty acids is accompanied by a shift in the position of double bonds to form conjugated hydroperoxides, and the conjugated structure absorbs strongly at 232-234 nm (Kulas and Ackman, 2001). The CD values increased significantly $(p<0.05)$ in all samples, with the exception of the samples treated with GYE 0.1 and 0.2 , during the $7 \mathrm{~d}$ of storage and then it peaked and later decreased until the end of storage (Table 3). This agrees with results obtained after adding several other natural antioxidants, including almond skin (Teets and Were, 2008). Peña-Ramos and Xiong (2003) also noted that the concentration of conjugated dienes in cooked pork patties treated with whey and soy protein hydrolysates increase significantly on the first day, followed by a decrease thereafter. A similar trend in CD values was observed in studies by Frankel (1998), in which the development of conjugated dienes, which parallels hydroperoxide production, exists in the early stages of lipid oxidation. Furthermore, Juntachote et al. (2006) reported that a decrease in $\mathrm{CD}$ values was followed by an increase in TBARS values in cooked ground pork.

The malondialdehyde (MDA) contents in raw chicken nugget batters stored for $0,3,7$, and $10 \mathrm{~d}$ is shown in Table 3. TBARS is a measure of secondary oxidation products, mainly aldehydes and carbonyls of hydrocarbons that contribute to off-flavors and flavours in meat
(Cho and Rhee, 1997). TBARS values increased significantly in control raw chicken nugget batter $(p<0.05)$. However, when GYE was added, the raw chicken nugget batter resisted lipid oxidation, and the TBARS values of all treated samples were much lower $(p<0.05)$ than the control on all days. The GYE treatment $(0.2 \%)$ suppressed lipid oxidation more than the ascorbic acid treatment $(p<0.05)$. This effect may be associated with GYE concentration because the highest concentration $(0.2 \%$ GYE) delayed the oxidation process most efficiently by maintaining TBARS values during the $10 \mathrm{~d}$ of storage. Similar TBARS values were reported by Sayago-Ayerdi et al. (2009) in raw and cooked chicken hamburgers who investigated the effects of antioxidants on dietary fiber. Mugwort contains many ingredients with antioxidant and antimicrobial effects such as polyphenols (Yun et al., 2008). Thus, the antioxidant effect of GYE may be related to its phenolic constituents. Several studies have noted a relationship between phenolic content and antioxidant activity (Velioglu et al., 1998). Sheard et al. (2000) recommended $0.5 \mathrm{mg} / \mathrm{kg}$ TBARS as a threshold value for rancidity perception by consumers. The TBARS values of all raw chicken nugget batter samples did not exceed 0.5 $\mathrm{mg} / \mathrm{kg}$ by the end of the storage period.

Adding GYE to raw chicken nugget batter inhibited lipid oxidation during $10 \mathrm{~d}$ of refrigerated storage. These 
data strongly suggest that GYE has potential as a natural antioxidant source for meat and meat products. Due to concerns regarding the safety and toxicity of synthetic antioxidants, Ganghwayakssuk may prove useful as a safe, natural health promoting antioxidant for the meat industry. GYE showed potential as a good natural antioxidant source that can be used as a functional ingredient for chicken nugget batter. Chicken nugget batter with added GYE could be a commercially acceptable meat product and can be readily manufactured with high quality. The best results were obtained using raw chicken nugget batter with $0.2 \%$ of added GYE.

\section{Acknowledgements}

This research was supported (608001-05-2-SB310) by Rural Development Administration (Republic of Korea). The authors also were partially supported by the Brain Korean 21 (BK 21) Project from Ministry of Education and Human Resources Development (Republic of Korea).

\section{References}

1. Ahn, D. U. and Nam, K. C. (2004) Effects of ascorbic acid and antioxidants on color, lipid oxidation and volatiles of irradiated ground beef. Radiat. Phys. Chem. 71, 149-154.

2. Antonia, H., Juan, F. B., and Ralael, G. (1990) Cellulase inhibition by polyphenols and olive fruits. Food Chem. 38, 6973.

3. AOAC (1990) Official methods of analysis. 16th ed. Association of Official Analytical Chemists, Washington, DC, USA.

4. Brand-Williams, W., Cuvelier, M. E., and Berset, C. (1995) Use of a free radical method to evaluate antioxidant activity. LWT-Food Sci. Technol. 28, 25-30.

5. Branen, A. L. (1975) Toxicology and biochemistry of butylated hydroxyanisole and butylated hydroxytoluene. J. Am. Oil Chem. Soc. 52, 59-63.

6. Cha, J. Y., Ahn, H. Y., Eom, K. E., Pack, B. K., Jun, B. S., and Cho, Y. S. (2009) Antioxidative activity of Aralia elata shoot and leaf extracts. J. Life Sci. 19, 652-658.

7. Chang, L. W., Yen, W. J., Huang, S. C., and Duh, P. D. (2002) Antioxidant activity of sesame coat. Food Chem. 78, 347354.

8. Cho, S. H. and Rhee, K. S. (1997) Lipid oxidation in mutton: species-related and warmed-over flavors. J. Food Lipids 4, 283-293.

9. Choi, Y. S., Choi, J. H., Han, D. J., Kim, H. Y., Lee, M. A., Kim, H. W., Song, D. H., Lee, J. W., and Kim, C. J. (2010) Effects of chestnut (Castanea sativa Mill.) peel powder on quality characteristics of chicken emulsion sausages. Korean J. Food Sci. Ani. Resour. 30, 755-763.

10. Cuvelier, M. E., Richard, H., and Berset, C. (1992) Comparison of the antioxidative activity of some acid-phenols: struc- ture-activity relationship. Biosci. Biotech. Biochem. 56, 324325.

11. Duh, P. D. (1998) Antioxidant activity of Budrock (Arctium lappa L.): Its scavenging effects on free radical and active oxygen. J. Am. Oil Chem. Soc. 75, 455-461.

12. El-Alim, S. S., Lugasi, A., Hovari, J., and Dworschak, E. (1999) Culinary herbs inhibit lipid oxidation in raw and cooked minced meat patties during storage. J. Sci. Food Agric. 79, 277-285.

13. Folch, J., Lee, M., and Stanley, S. G. H. (1957) A simple method for the isolation and purification of total lipids from animal tissues. J. Biol. Chem. 226, 497-509.

14. Frankel, E. N. (1998) Lipid oxidation. The Oily Press Ltd. Dundee, Scotland.

15. Goulas, A. E. and Kontominas, M. G. (2007) Combined effect of light salting, modified atmosphere packaging and oregano essential oil on the shelf-life of sea bream (Sparus aurata): Biochemical and sensory attributes. Food Chem. 100, 287-296.

16. Graf, E. and Eaton, J. W. (1990) Antioxidant functions of phytic acid. Free Radic. Biol. Med. 8, 61-69.

17. Gwon, S. Y. and Moon, B. K. (2009) The quality characteristics of sulgidduk prepared with green tea or rosemary powder. Korean J. Soc. Food Cookery Sci. 25, 150-159.

18. Han, M. J., Shin, J. E., Han, Y. O., Kim, N. Y., and Lee, K. H. (2001) The effect of mugwort and storage on quality characteristics of ssookgaedduck. Korean J. Soc. Food Cookery Sci. 17, 634-638.

19. Hettiarachchy, N. S., Glenn, K. C., Gnanaesbandam, R., and Johnson, M. G. (1996) Natural antioxidant extracts from fenugreek (Trigonella foenumgraecum) for ground beef patties. J. Food Sci. 61, 516-519.

20. Hong, J. H., Jeon, J. L., Lee, J. H., and Lee, I. S. (2007) Antioxidative Properties of Artemisia princeps Pamp. J. Korean Soc. Food Sci. Nutr. 36, 657-662.

21. Jeong J. A., Kwon, S. H., and Lee, C. H. (2007) Screening for antioxidative activities of extracts from aerial and underground parts of some edible and medicinal ferns. Korean $J$. Plant Res. 20, 185-192.

22. Jung, I. C., Moon, Y. H., and Kang, S. J. (2004) Storage stability of pork patty with mugwort powder. J. Life Sci. 14, 198-203.

23. Juntachote, J., Berghofer, E., Siebenhandl, S., and Bauer, F. (2006) The antioxidative properties of holy basil and galangal in cooked ground pork. Meat Sci. 72, 446-456.

24. Juntachote, T., Berghofer, S., Siebenhandl, S., and Bauer, F. (2007) The effect of dried galangal powder and its ethanolic extracts on oxidative stability in cooked ground pork. LWTFood Sci. Technol. 40, 324-330.

25. Kikuzaki, H. and Nakatani, N. (1993) Antioxidant effects of some ginger constituents. J. Food Sci. 58, 1407-1410.

26. Kim, J. S. (2006) Effect of mugwort and fish oil addition on quality and shelf-life in meat-type chicken. Korean J. Poult. Sci. 33, 1-6.

27. Kulas, E. and Ackman, R. G. (2001) Different tocopherols and the relationship between two methods for determination 
of primary oxidation products in fish oil. J. Agric. Food Chem. 49, 1724-1729.

28. Lee, S. J., Chung, H. Y., Lee, I. K., and Yoo, I. D. (1999) Isolation and identification of flavonoids from ethanol extracts of Artemisia vularis and their antioxidant activity. Korean $J$. Food. Sci. Technol. 31, 815-822.

29. Mathew, S. and Abraham, E. T. (2006) Studies on the antioxidant activities of cinnamon (Cinnamonum verum) bank extracts, through various in vitro models. Food Chem. 94, 520-528.

30. Morrissey, P. A., Sheehy, P. J. A., Galvin, K., Kerry, J. P., and Buckley, D. J. (1998) Lipid stability in meat and meat products. Meat Sci. 49, 73-86.

31. Osburn, W. N. and Keeton, J. T. (1994) Konjac flour gel as fat substitute in low-fat prerigor fresh pork sausage. J. Food Sci. 59, 484-489.

32. Oyaizu, M. (1986) Studies on product of browning reaction prepared from glucosamine. Jap. J. Nut. 44, 307-315.

33. Park, B. H., Jeon, E. R., Kim, S. D., and Cho, H. S. (2010) Quality characteristics of dried noodle added with Lotus leaf powder. Korean J. Food Culture 25, 225-231.

34. Park, C. S. and Kim, M. L. (2006) Functional properties of mugwort extracts and quality characteristics of noodle added mugwort powder. Korean J. Food Preserv. 13, 161-167.

35. Park, C. S., Kwon, C. J., Choi, M. A., Park, G. S., and Choi, K. H. (2002) Antioxidative and nitrite scavenging activities of mugwort and find needle extracts. Korean J. Food Preserv. 9, 248-252.

36. Park, J. H., Kim, Y. M., and Kim, S. M. (2006) Effect of setting on the texture intensity of smoked alaska pollock roe sausage with cellulose casing and its quality characteristics during storage. J. Korean Soc. Food Sci. Nutr. 35, 96-103

37. Peña-Ramos, E. A. and Xiong, Y. L. (2003) Whey and soy protein hydrolysates inhibit lipid oxidation in cooked pork patties. Meat Sci. 64, 259-263.

38. Prasetyo, M., Chia, M., Hughey, C., and Were, L. M. (2008) Utilization of electron beam irradiated almond skin powder as a natural antioxidant in ground top round beef. J. Food Sci. 73, T1-T6.

39. Pratt, D. E. and Hudson, B. J. F. (1990) Natural antioxidants not exploited commercially. In: Food antioxidants, Hudson B. J. F. (ed). Elsevier, Amsterdam, pp. 171-192.

40. Ruy, S. N., Han, S. S., Yang, J. J., Jeong, H. G., and Kang, S. S. (2005) Variation of eupatilin and jaceosidin content of mugwort. J. Crop Sci. 50, 204-207.

41. Ruy, S. N., Kang, S, S., Kim, S. J., and Ku, B. L. (2004) Quantitative analysis of epatulin and jaceosidin in Artemisia herba. Korean J. Intl. Agri. 20, 308-314.

42. SAS (2001) SAS user's guide: Basic statistical analysis. SAS Institute Inc., Cary, NC, USA.

43. Sáyago-Ayerdi, S. G., Brenes, A., and Goñi, A. (2009) Effect of grape antioxidant dietary fiber on the lipid oxidation of raw and cooked chicken hamburgers. LWT-Food Sci. Tech- nol. 42, 971-976.

44. Shahidi, F. and Wanasundara, P. K. J. (1992) Phenolic antioxidants. Crit Rev. Food Sci. Nutr. 32, 67-103.

45. Sheard, P. R., Enser, M., Wood, J. D., Nute, G. R., Gill, B. P., and Richardson, R. I. (2000) Shelf life and quality of pork and pork products with raised n-3 PUFA. Meat Sci. 55, 213221.

46. Shimada, K., Fujikawa, K., Yahara, K., and Nakamura, T. (1992) Antioxidative properties of xanthan on the autoxidation of soybean oil in cyclodextrin emulsion. J. Agric. Food Chem. 40, 945-948.

47. Slinkard, K. and Sighleton, V. L. (1997) Total phenol analysis: automation and comparison with manual methods. Am. J. Enol. Vitic. 28, 49-55.

48. Tang, S., Kerry, J. P., Sheehan, D., Buckley, D. J., and Morrissey, P. A. (2001) Antioxidative effect of added tea catechins on susceptibility of cooked red meat poultry and fish patties to lipid oxidation. Food Res. Int. 34, 651-657.

49. Tarladgis, B. G., Watts, B. M., Younthan, M. T., and Dugan, L. R. (1960) A distillation method for the quantitative determination of malonaldehyde in rancid foods. J. Am. Oil Chemist Soc. 37, 403-406.

50. Teets, A. S. and Were, L. M. (2008) Inhibition of lipid oxidation in refrigerated and frozen salted raw minced chicken breasts with electron beam irradiated almond skin powder. Meat Sci. 80, 1326-1332.

51. Velioglu, Y. S., Nazza, G., Gao, L., and Oomah, B. D. (1998) Antioxidant activity and total phenolics in selected fruits, vegetables and grain products. J. Agric. Food Chem. 46, 4113-4117.

52. Verhagen, H., Deerenberg, I., Marx, A., Ten Hoor, F., Henderson, P. T., and Kleinjans, J. C. S. (1994) Estimate of the daily dietary intake of butylated hydroxyanisole and butylated hydroxytoluene in the Netherlands. Food Chem. Toxicol. 28, 215-220.

53. Woo, J. H., Shin, S. L., and Lee, C. H. (2010) Antioxidant effects of ethanol extracts from flower species of compositae plant. J. Korean Soc. Food Sci. Nutr. 39, 159-164.

54. Woo, S. M. and Jeong, Y. J. (2006) Effect of germinated brown rice concentrate on free amino acid levels and antioxidant and nitrite scavenging activity in kimchi. Food Sci. Biotechnol. 15, 351-356.

55. Yen, G. C. and Chung, D. Y. (1999). Antioxidant effects of extracts from Cassia Tora L. prepared under different degrees of roasting on the oxidative damage to biomolecules. J. Agric. Food Chem. 47, 1326-1332.

56. Yun, K. W., Jeong, H. J., and Kim, J. H. (2008) The influence of the growth season on the antimicrobial and antioxidative activity in Artemisia princeps var. orientalis. Ind. Crop. Prod. 27, 69-74.

(Received 2010.12.23/Revised 2011.1.20/Accepted 2011.1.22) 